\title{
Intravitreal Adenoviral 15-Lipoxygenase-1 Gene Transfer Prevents Vascular Endothelial Growth Factor A-Induced Neovascularization in Rabbit Eyes
}

\author{
Helena Viita, Kati Kinnunen, Emmi Eriksson, Johanna Lähteenvuo,, Mohan Babu,' Giedrius Kalesnykas,,2 \\ Tommi Heikura, Svetlana Laidinen,' Teemu Takalo,, and Seppo Ylä-Herttuala'1,3,4
}

\begin{abstract}
Excessive angiogenesis mediated by vascular endothelial growth factor (VEGF) plays an important role in angioproliferative ocular diseases. We have previously developed a large animal model for these diseases by intravitreal adenoviral gene transfer of VEGF-A ${ }_{165}$. 15-Lipoxygenase-1 (15-LO-1), an oxidizing enzyme producing reactive lipid hydroperoxides, has been shown to induce aberrant angiogenesis in cancer models of transgenic mice overexpressing human 15-LO-1. Our purpose was to study the effects of 15-LO-1 on VEGF- $\mathrm{A}_{165^{-}}$ induced angiogenesis in New Zealand White rabbit eyes, using intravitreal adenovirus-mediated gene transfers. AdCMV and Adh15-LO-1 alone served as controls. As determined by immunohistochemistry, VEGF- $\mathrm{A}_{165}$ significantly increased the number and size of the capillaries in various compartments of the eyes. 15-LO-1 efficiently inhibited VEGF- $\mathrm{A}_{165}$-induced neovascularization and pathological changes by reducing VEGF- $\mathrm{A}_{165}$ mRNA and protein expression, determined by RT-PCR, ELISA, and immunohistochemistry. 15-LO-1, which produces endogenous ligands for peroxisome proliferator-activated receptor- $\gamma$ (PPAR $\gamma$ ), also prevented VEGF$\mathrm{A}_{165}$-induced expression of PPAR $\gamma$ and VEGF receptor-2, as measured by quantitative RT-PCR. In conclusion,

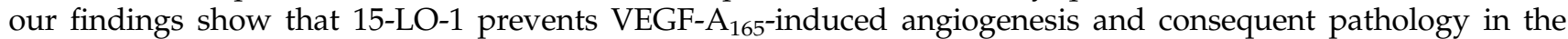
eyes, suggesting that intravitreal 15-LO-1 gene transfer could be a potential new strategy for the treatment of neovascular complications in the eyes.
\end{abstract}

\section{Introduction}

$\mathbf{H}$ UMAN 15-LIPOXYGENASE-1 (15-LO-1) is a lipid-peroxidizing enzyme capable of introducing molecular oxygen to polyunsaturated fatty acids either in free form or in more complex substrates, such as biological membranes, phospholipids, cholesterol esters, and plasma lipoproteins (Chanez et al., 2002; Kuhn et al., 2002). The primary 15-LO-1 products from arachidonic acid and linoleic acid are (15S)-hydroperoxyeicosatetraenoic acid and (13S)hydroperoxyoctadecadienoic acid, respectively (Chanez et al., 2002). 15-LO-1 belongs to the class of reticulocyte-type lipoxygenases, which under basal conditions are expressed mainly in reticulocytes, eosinophils, and airway epithelial cells (Nadel et al., 1991). In reticulocytes, 15-LO-1 reacts with the mitochondrial membrane lipids initiating the controlled breakdown of mitochondria during the reticulocyte maturation process (Kroschwald et al., 1989). Programmed organelle degradation is also induced by $15-\mathrm{LO}-1$ in the eye during differentiation of the central fiber cells of the eye lens (van Leyen et al., 1998). Because of its potential to produce reactive oxygen species and lipid hydroperoxides, 15-LO-1 may act on several different signal transduction pathways and thus affect the expression levels of a number of different genes (Viita and Ylä-Herttuala, 2000). 15-LO-1 and its products are involved in many pathological conditions, such as skin and respiratory symptoms in allergic diseases, in inflammation, atherogenesis, and carcinogenesis (Kuhn et al., 2002). However, some results are controversial, and for example, the pro- or antitumorigenic roles of 15-LO-1 seem to depend on the tumor type (Kuhn and Chan, 1997; Cathcart and Folcik, 2000; Pidgeon et al., 2007).

\footnotetext{
${ }^{1}$ Department of Biotechnology and Molecular Medicine, A.I. Virtanen Institute for Molecular Sciences, University of Kuopio, FI-70211 Kuopio, Finland.

${ }^{2}$ Department of Ophthalmology, Institute of Clinical Medicine, University of Kuopio, FI-70211 Kuopio, Finland.

${ }^{3}$ Department of Medicine, University of Kuopio, Kuopio, FI-70211 Finland.

${ }^{4}$ Gene Therapy Unit, Kuopio University Hospital, Kuopio, FI-70211 Finland.
} 
Vascular endothelial growth factors (VEGFs) play a pivotal role in physiological angiogenesis, but they also induce excessive angiogenesis in many pathological conditions, such as ocular diseases. The most important angioproliferative ocular diseases are diabetic proliferative retinopathy and age-related macular degeneration (Witmer et al., 2003). Our group has previously developed a model for ocular angioproliferative diseases by showing that intravitreal adenoviral gene transfer of VEGF-A $\mathrm{A}_{165}$ induces neovascularization and increases vascular leakage, resembling structural changes detected in diabetic retinopathy (Kinnunen et al., 2006).

In this work, we show that 15-LO-1 efficiently prevents angiogenic effects induced by VEGF- $\mathrm{A}_{165}$. $15-\mathrm{LO}-1$ prevented VEGF-A $A_{165}$-induced increase in the number and size of the capillaries in various compartments of the eyes, thus inhibiting VEGF-A 165 -induced neovascularization and pathological changes. VEGF-A $\mathrm{A}_{165}$ expression was prevented by $15-\mathrm{LO}-1$ at the mRNA level, resulting in low production of VEGF-A protein. VEGF-A mediates its signaling effects mainly via VEGF receptor (VEGFR)-2, which is induced by peroxisome proliferator-activated receptor (PPAR)- $\gamma$. We show that the mRNA expression of PPAR $\gamma$ and VEGFR2 is induced by VEGF-A $A_{165}$, but that the inductions are efficiently inhibited by 15-LO-1. Thus, 15-LO-1 gene transfer is a potential new strategy for the treatment of pathological angiogenesis in the eyes.

\section{Materials and Methods}

\section{Production of recombinant adenoviruses}

The expression cassette of recombinant adenovirus Adh15LO-1 contains nucleotides 1-2245 of human 15-LO-1 cDNA (Sigal et al., 1988) under the control of the human cytomegalovirus (CMV) immediate-early enhancer/promoter and intron with splicing signals, followed by bovine growth hormone transcriptional terminator and poly(A) signal sequences (Aggarwal et al., 2007). AdhVEGF-A 165 (Rissanen et al., 2003b) contains the CMV immediate-early promoter/ enhancer region, the coding sequence for human VEGF- $\mathrm{A}_{165}$, and the human growth hormone poly(A) signal. Recombinant adenoviruses containing nuclear-targeted Escherichia coli lacZ gene (AdlacZ) (Laitinen et al., 1998) or the CMV promoter without any insert (AdCMV) (Kinnunen et al., 2006) were used as controls in the in vitro and in vivo gene transfers, respectively. All recombinant adenoviruses were produced in 293 cells (Graham et al., 1977) by homologous recombination as described (Laitinen et al., 1998).

\section{5-LO-1 activity assay}

The capacity of the recombinant Adh15-LO-1 virus to produce functionally active $15-\mathrm{LO}-1$ protein was verified from in vitro-transduced ECV304 cells $72 \mathrm{hr}$ after transduction by gas chromatographic hydroxy fatty acid analysis as described (Viita et al., 2008).

\section{Intravitreal gene transfer into rabbit eyes}

New Zealand White rabbits $(n=32)$ were anesthetized as described (Kinnunen et al., 2006). The animals received intravitreal injections of a total of $1.0 \times 10^{11}$ viral particles (AdCMV, Adh15-LO-1, AdhVEGF-A $\mathrm{A}_{165}$, and a combination of Adh15-LO-1 with AdhVEGF-A ${ }_{165}$ [treatment group]) in a total volume of $100 \mu \mathrm{l}$. The injections were performed intravitreally
(Kinnunen et al., 2006) by injecting AdCMV alone $\left(1 \times 10^{11}\right.$ viral particles [VP]) and AdhVEGF-A $165\left(0.5 \times 10^{11} \mathrm{VP}\right)$ plus AdCMV $\left(0.5 \times 10^{11} \mathrm{VP}\right)$, or Adh15-LO-1 $\left(0.5 \times 10^{11} \mathrm{VP}\right)$ plus AdCMV $\left(0.5 \times 10^{11} \mathrm{VP}\right)$ and the combination of Adh15-LO-1 $\left(0.5 \times 10^{11} \mathrm{VP}\right)$ and AdhVEGF-A $165\left(0.5 \times 10^{11} \mathrm{VP}\right)$ into the left and right eyes of the same animal, respectively. The animals were killed 6 days after the gene transfers, when the concentration of the transduced human VEGF-A protein was maximal in the vitreous humor (Kinnunen et al., 2006). All animal experiments were approved by the Experimental Animal Committee of the University of Kuopio (Kuopio, Finland).

Fundus photographs of rabbit eyes were taken before gene transfer and 1 day before sacrifice, and vitreous samples were collected from each eye after sacrifice as described (Kinnunen et al., 2006). One set of animals ( $n=5$ per group) was perfusion fixed (Rissanen et al., 2003a). The eyes were enucleated and cut in half. One half was immersion fixed in $4 \%$ paraformaldehyde in $7.5 \%$ sucrose $(\mathrm{pH} 7.4$ ) for $4 \mathrm{hr}$, rinsed in $15 \%$ sucrose ( $\mathrm{pH} 7.4$ ) overnight, and embedded in paraffin (Kinnunen et al., 2006). Another set of animals $(n=5$ per group) was killed without perfusion fixation. The eyes were enucleated and cut in half from the side of the optic nerve. The half containing the optic nerve was processed for frozen sections and the other half was cut into longitudinal segments, which contained parts from the back of the eye all the way to the cornea, that is, parts of the outer layer (sclera and cornea), the middle layer (choroid, ciliary body, and the iris), and the innermost layer (the retina). The segments were snap-frozen in liquid nitrogen and stored at $-70^{\circ} \mathrm{C}$ for RNA analysis. A third set of animals ( $n=6$ per group) was killed without perfusion fixation, the superior part of the eyes was identified for orientation, the eyes were enucleated, and the retinal whole mounts were detached from the sclera and postfixed for $24 \mathrm{hr}$ in the same fixative solution.

\section{Immunohistochemistry}

Immunohistochemical analysis of capillaries was performed on serial paraffin-embedded sections, using a mouse monoclonal antibody against human CD31 (diluted 1:50; Dako, Glostrup, Denmark). Capillary mean area $\left(\mu \mathrm{m}^{2}\right)$ and capillary density (capillaries per $\mathrm{mm}^{2}$ ) in the optic nerve head, retina, and anterior segments were measured as described (Kinnunen et al., 2006). Expression of transduced VEGF-A protein was detected by immunohistochemistry as described (Viita et al., 2008).

Whole mounts of retinas were incubated with fluorescein isothiocyanate (FITC)-conjugated lectin (Lycopersicon esculentum [tomato], diluted 1:200; Sigma-Aldrich, St. Louis, MO) overnight at room temperature. The retinas were then washed in $0.05 M$ Tris-buffered saline ( $\mathrm{pH} 7.4$ ) containing $0.5 \%$ Triton, three times for $15 \mathrm{~min}$, and incubated with mouse monoclonal anti-glial fibrillary acidic protein (GFAP, diluted 1:1000; Sigma-Aldrich) for $24 \mathrm{hr}$ at room temperature and with goat anti-mouse IgG (Alexa Fluor 594, diluted 1:500; Molecular Probes/Invitrogen, Eugene, OR) for $3 \mathrm{hr}$ at room temperature. The stained retinas were flat mounted on a glass slide in glycerol and coverslipped.

\section{Measurements of retinal blood vessels}

Four peripheral areas of medullary rays from each wholemounted retina were digitally imaged with a DP50 camera 


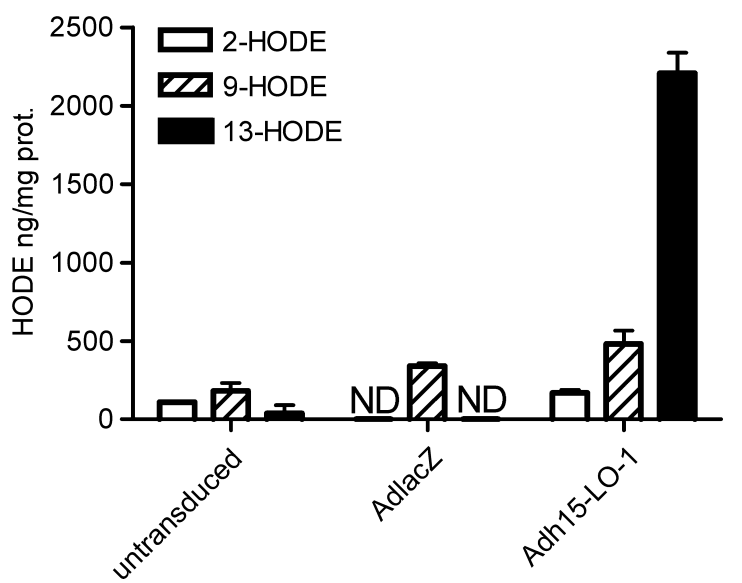

FIG. 1. Gas chromatographic 15-lipoxygenase-1 (15-LO-1) enzyme activity analysis from in vitro-transduced ECV304 cells after incubation with linoleic acid. Untransduced, AdlacZtransduced, and Adh15-LO-1-transduced cells were lysed and incubated with $50 \mu \mathrm{M}$ linoleic acid for $15 \mathrm{~min}$ at $37^{\circ} \mathrm{C}$. Results are presented as nanograms of hydroxyoctadecadienoic acid (HODE) per milligram of protein $\pm S D, n=2$ per group. ND, not detectable.

system (Olympus, Tokyo, Japan) operating on a BX40 microscope (Olympus). Retinal blood vessel diameters were measured with Adobe Photoshop CS3 software (Adobe Systems, San Jose, CA).

\section{Human VEGF-A enzyme-linked immunosorbent assay}

Production of transduced human VEGF-A protein was quantified by enzyme-linked immunosorbent assay (ELISA) (Quantikine human VEGF-A; R\&D Systems, Minneapolis, $\mathrm{MN}$ ) from snap-frozen vitreous samples according to the manufacturer's instructions. The results are presented as picograms of VEGF-A per milliliter.

\section{Reverse transcription-polymerase chain reaction ( $R T-P C R)$ and quantitative $R T-P C R$}

Total RNA was isolated and RT-PCR for transduced human VEGF-A, transduced human 15-LO-1, and endogenous rabbit $\alpha$-actin was performed as described (Viita et al., 2008). The primers for human 15-LO-1 are specific for the transferred gene, because the $5^{\prime}$ primer binds to the CMV promoter area of the adenoviral vector $5^{\prime}$ to the splice signals and the $3^{\prime}$ primer binds to the cloning junction of 15-LO-1. These primers result in the amplification of a 956-bp fragment from the unspliced Adh15-LO-1 vector and of a 129-bp fragment from the spliced mRNA produced from the recombinant Adh15-LO-1 virus. Quantitative RT-PCR was used to quantify the mRNA expression of endogenous rabbit PPAR $\gamma$ and VEGFR2 as described (Viita et al., 2008). Twentyfive and $2.5 \mathrm{ng}$ of cDNA were used as the template for $\operatorname{PPAR} \gamma$ and VEGFR2 reactions, respectively.

\section{Statistics}

Results are presented as means \pm SD. Statistical significance was evaluated with the GraphPad Prism 4.00 software package, using one-way analysis of variance (ANOVA) followed by the Newman-Keuls multiple comparison test or the Kruskal-Wallis test when necessary. A value of $p<0.05$ was considered statistically significant.

\section{Results}

\section{Adh15-LO-1 produces enzymatically active 15-LO-1}

Verification of the functionality of the recombinant Adh15LO-1 virus was confirmed from in vitro-transduced ECV304 cells by gas chromatographic enzyme activity analysis after incubation of the cells with linoleic acid. Production of the

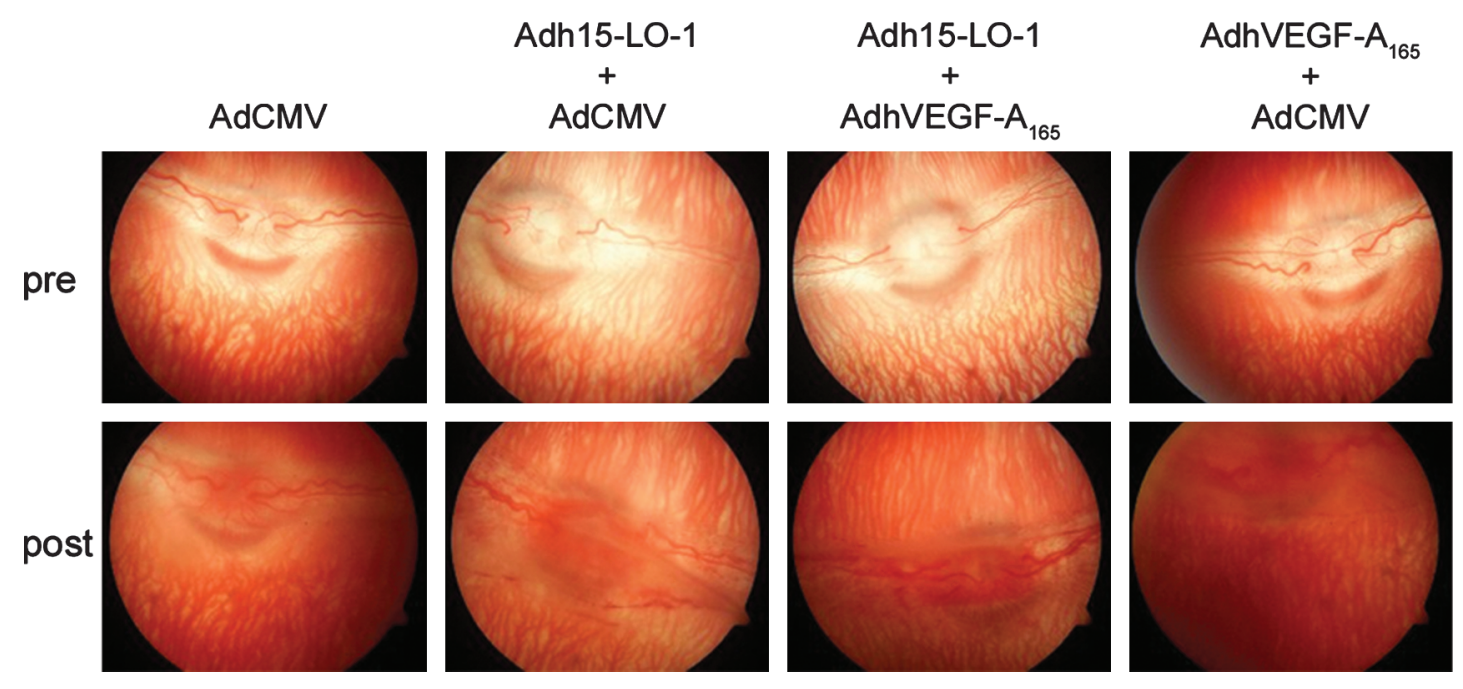

FIG. 2. Adh15-LO-1 prevents AdhVEGF-A 165 -induced vascular effects. Top: Rabbit fundus photographs before the gene transfers (pre) show that the eyes were calm in all groups. Bottom: Five days after the gene transfers (post) the eyes remained fairly calm in the AdCMV, Adh15-LO-1 plus AdCMV, and Adh15-LO-1 plus AdhVEGF-A 165 gene transfer groups, whereas increased neovascularization detected in the AdhVEGF- $\mathrm{A}_{165}$ plus AdCMV gene transfer group made evaluation of the retinal vessels difficult. 


\section{Papilla}
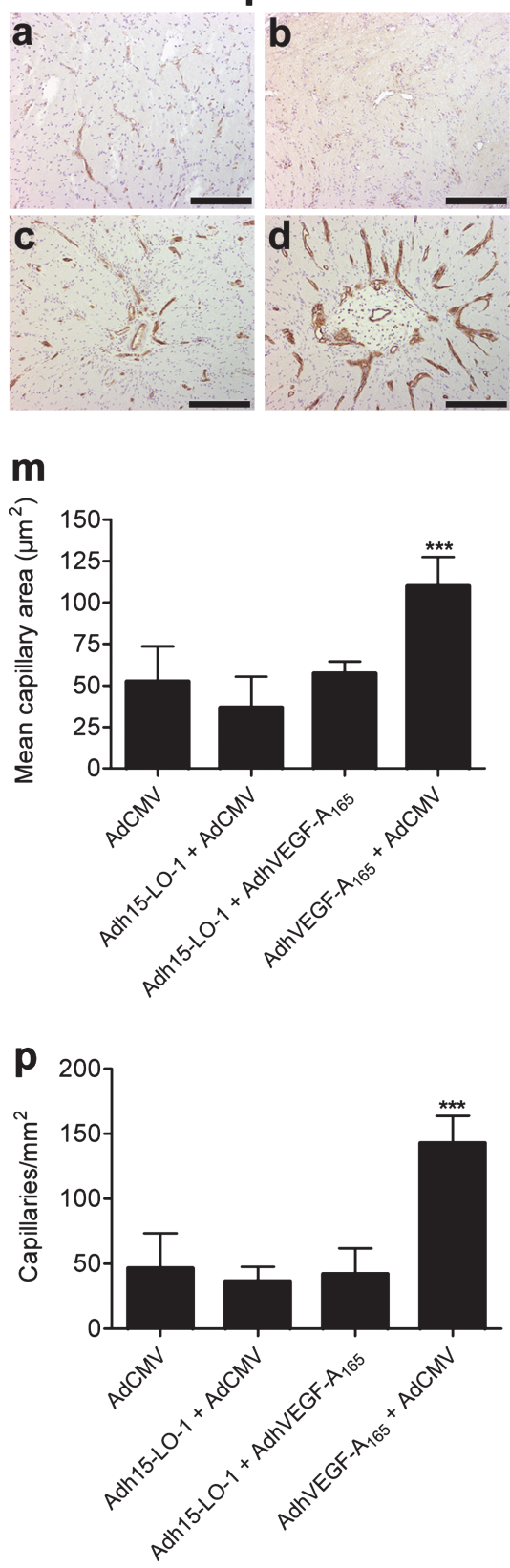

Retina
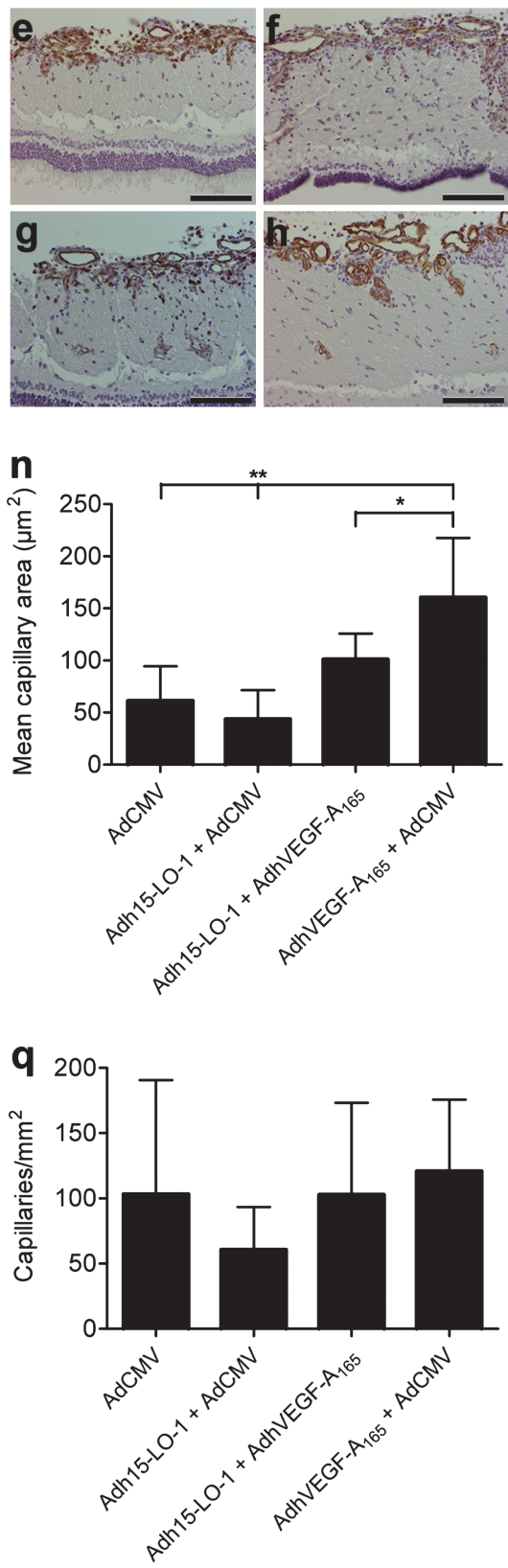

Anterior
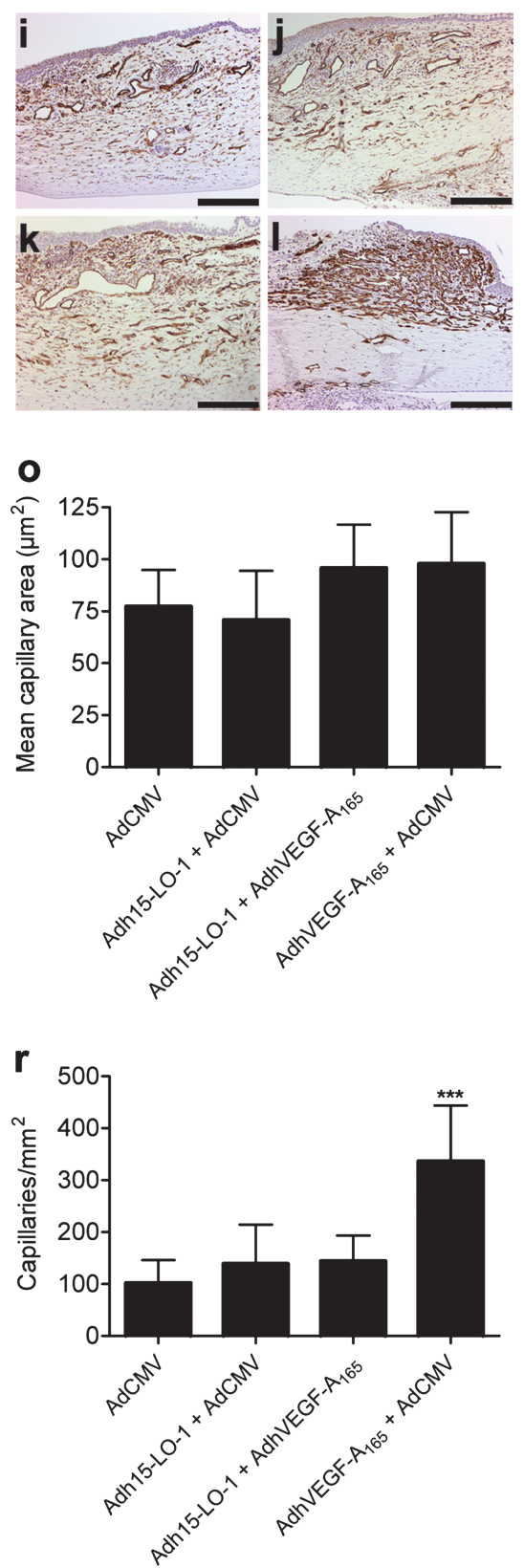

FIG. 3. Adh15-LO-1 prevents AdhVEGF-A 165 -induced capillary enlargement and increase in capillary number. Immunohistochemical staining for CD31 was done in papilla, retina, and anterior segment. (a, e, and $\mathbf{i})$ AdCMV; (b, f, and $\mathbf{j})$ Adh15-LO-1 plus AdCMV; (c, g, and k) Adh15-LO-1 plus AdhVEGF-A $165 ;(\mathbf{d}, \mathbf{h}$, and 1) AdhVEGF-A 165 plus AdCMV. For papilla (a-d) and anterior segment (i-1) the original magnification was $\times 100$ (scale bars, $100 \mu \mathrm{m}$ ). For retina (e-h) the original magnification was $\times 200$ (scale bars, $50 \mu \mathrm{m}$ ). AdhVEGF-A ${ }_{165}$ induced significant increases in the mean capillary area $\left(\mu \mathrm{m}^{2}\right)$ in the papilla (m) ( $p<0.001$ vs. all other groups) and in the retina (n) (** $p<0.01$ vs. AdCMV and Adh15-LO-1, * $p<0.05$ vs. the 15-LO-1 treatment group), and this induction was prevented in the 15-LO-1 treatment group. No effects on capillary size could be detected in the anterior segment (o). Capillary number was increased by AdhVEGF-A 165 in the papilla (p) $\left({ }^{* * *} p<0.001\right.$ vs. all other groups) and in the anterior segment $(\mathbf{r})\left({ }^{* * *} p<0.001\right.$ vs. all other groups), and this induction was prevented in the 15-LO-1 treatment group. No effects on the capillary number could be detected in the retina (q).

specific 15-LO-1 reaction product 13-hydroxyoctadecadienoic acid (13-HODE) was highly increased in Adh15-LO-1transduced cells $72 \mathrm{hr}$ after transduction as compared with untransduced or AdlacZ-transduced cells (Fig. 1). The proportion of 13-HODE of all the HODEs detected was $77 \%$ in Adh15-LO-1-transduced cells.

\section{Adh15-LO-1 prevents AdhVEGF-A $A_{165}$-induced capillary enlargement and an increase in capillary number}

Fundus photographs from the rabbit eyes 5 days after the gene transfer showed highly induced neovascularization in 
AdhVEGF-A ${ }_{165}$-transduced eyes compared with all other groups (Fig. 2). Capillary analysis of CD31-immunostained paraffin sections showed that AdhVEGF-A 165 gene transfer resulted in a significant enlargement of the capillaries in the papilla (2.1-fold vs. control AdCMV; $p<0.001$ ) (Fig. 3a-d and $\mathrm{m})$ and in the retina (2.6-fold vs. control AdCMV; $p<0.01$ ) (Fig. $3 \mathrm{e}-\mathrm{h}$ and $\mathrm{n}$ ). In the 15-LO-1 treatment group, where Adh15LO-1 gene transfer was combined with AdhVEGF-A ${ }_{165}$, Adh15LO-1 prevented AdhVEGF- $\mathrm{A}_{165}$-induced capillary enlargement $(p<0.001$ in the papilla and $p<0.05$ in the retina) (Fig. $3 \mathrm{~m}$ and $n)$. No effect on the size of the capillaries was detected in the anterior segments (Fig. 3i-l and o). AdhVEGF-A 165 gene transfer significantly increased the average number of capillaries in the papilla (3.1-fold vs. control AdCMV; $p<0.001$ ) (Fig. 3a-d and p), and in the anterior segments (3.3-fold vs. control AdCMV; $p<0.001$ ) (Fig. 3i-1 and r), whereas Adh15-LO-1 prevented the increase in capillary number $(p<0.001$ in the papilla and $p<0.001$ in the anterior segment) (Fig. 3p and r). No effect on the number of capillaries was detected in the retina (Fig. 3e-h and q). Adh15-LO-1 alone had no effect on mean capillary area or capillary number (Fig. 3m-r).

Retinal blood vessel diameter was measured from wholemounted retinas immunostained with FITC-conjugated lectin. Intravitreal injections of AdhVEGF- $\mathrm{A}_{165}$ alone induced a significant increase in retinal blood vessel diameter (1.9-fold vs. control AdCMV; $p<0.001)$, whereas in the 15-LO-1 treatment group, Adh15-LO-1 prevented the capillary enlargement $(p<0.001)$ (Fig. 4a-d and i). No major differences between the study groups were observed in glial fibrillary acidic protein staining (Fig. 4e-h). However, intravitreal injections caused microglial activation in all study groups (data not shown).

\section{Adh15-LO-1 reduces the expression of transduced VEGF-A $A_{165} m R N A$, resulting in a significant reduction in the production of VEGF-A protein}

RT-PCR showed that expression of transduced human VEGF-A ${ }_{165}$ mRNA was reduced in 15-LO-1 treatment group samples compared with AdhVEGF-A ${ }_{165}$-transduced eyes (Fig. 5a). Expression of transduced, spliced 15-LO-1 mRNA was clearly seen as a 129-bp product both in Adh15-LO-1 group samples and in 15-LO-1 treatment group samples (Fig. 5b). 15-LO-1 RT-PCR also showed that there was no contaminating DNA, because the amplified PCR fragment from the 15-LO-1 adenoviral vector DNA would have been differently sized (956bp). Rabbit $\alpha$-actin RT-PCR showed equal expression in all samples (Fig. 5c).

The reduced expression of transduced human VEGF-A 165 transcript was also reflected in the human VEGF-A 165 ELISA. AdhVEGF-A $A_{165}$ gene transfer resulted in a large induction $(p<0.001)$ in the production of human VEGF-A 165 protein in the vitreous humor compared with control AdCMV (Fig. 5d), whereas in the 15-LO-1 treatment group the levels did not differ from the control AdCMV samples or the Adh15-LO-1transduced samples. The reduction in VEGF-A protein expression was also detected by immunohistochemistry (Fig. 5e).

\section{AdhVEGF- $A_{165}$-induced $m R N A$ expression of endogenous rabbit PPAR $\gamma$ and VEGFR2 is prevented by Adh15-LO-1}

Quantitative RT-PCR analysis was used to measure expression levels of endogenous rabbit PPAR $\gamma$ and VEGFR2
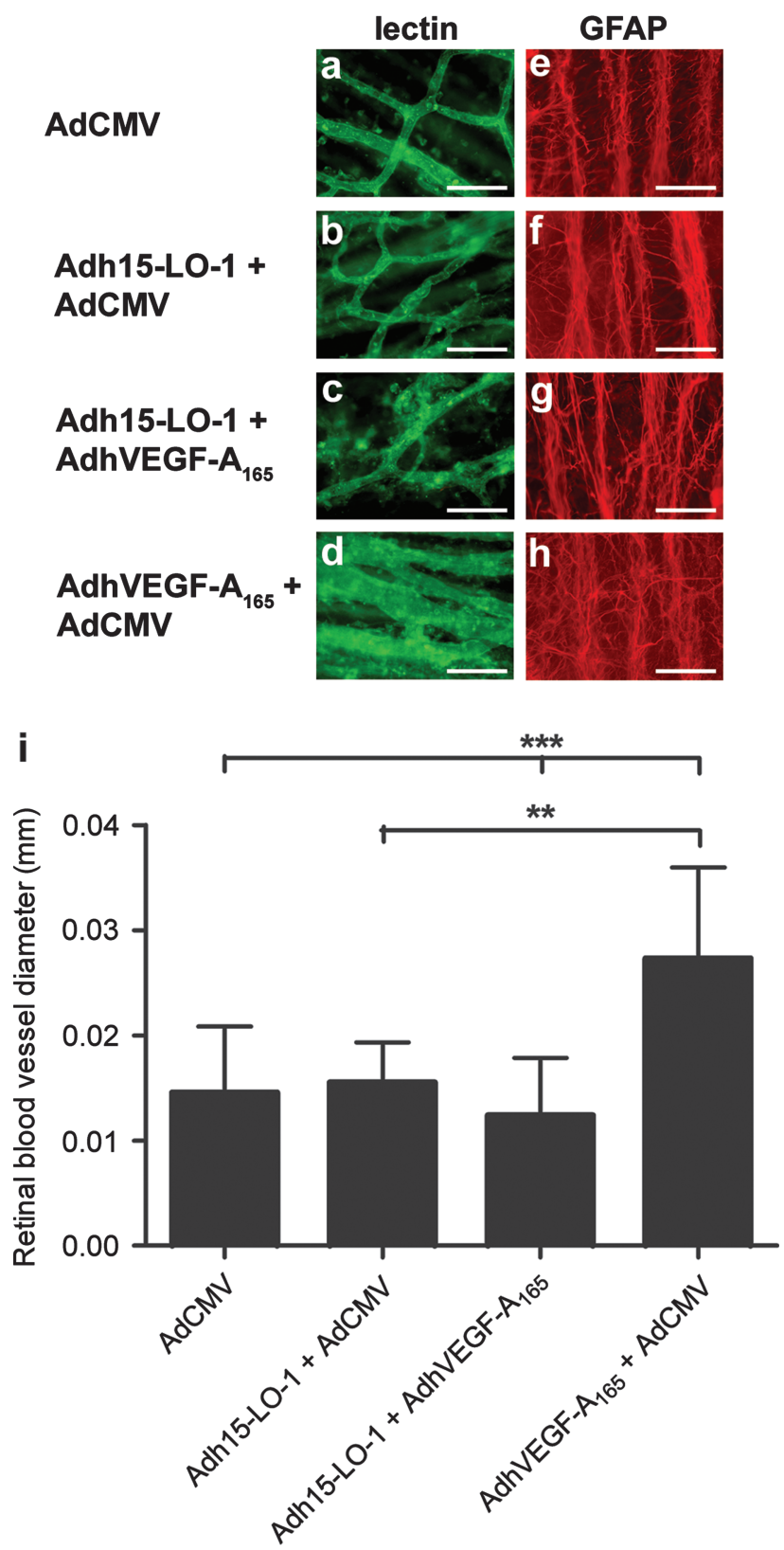

FIG. 4. Adh15-LO-1 blocks the AdhVEGF-A 165 -induced increase in retinal blood vessel diameter. Immunohistochemical staining of blood vessels $(\mathbf{a}-\mathbf{d})$ (lectin, green color; original magnification, $\times 200$; scale bar, $100 \mu \mathrm{m})$ and astrocytes (e-h) (glial fibrillary acidic protein [GFAP], red color; original magnification $\times 200$; scale bar, $100 \mu \mathrm{m}$ ) from flatmount retinas are shown. Intravitreal injections of AdhVEGF-A $_{165}$ induced a significant increase in retinal blood vessel diameter (i) $\left.{ }^{* *} p<0.01 ;{ }^{* * *} p<0.001\right)$, whereas this increase was efficiently prevented in the 15-LO-1 treatment group. Staining for GFAP did not reveal major differences between retinas $(\mathbf{e}-\mathbf{h})$.

mRNAs in the eye samples. AdhVEGF-A 165 gene transfer resulted in a 2.9-fold increase in PPAR $\gamma$ (Fig. 6a) and a 2.5fold increase in VEGFR2 (Fig. 6b) mRNA expression compared with the control AdCMV group. In the 15-LO-1 treatment group these inductions were efficiently prevented. 


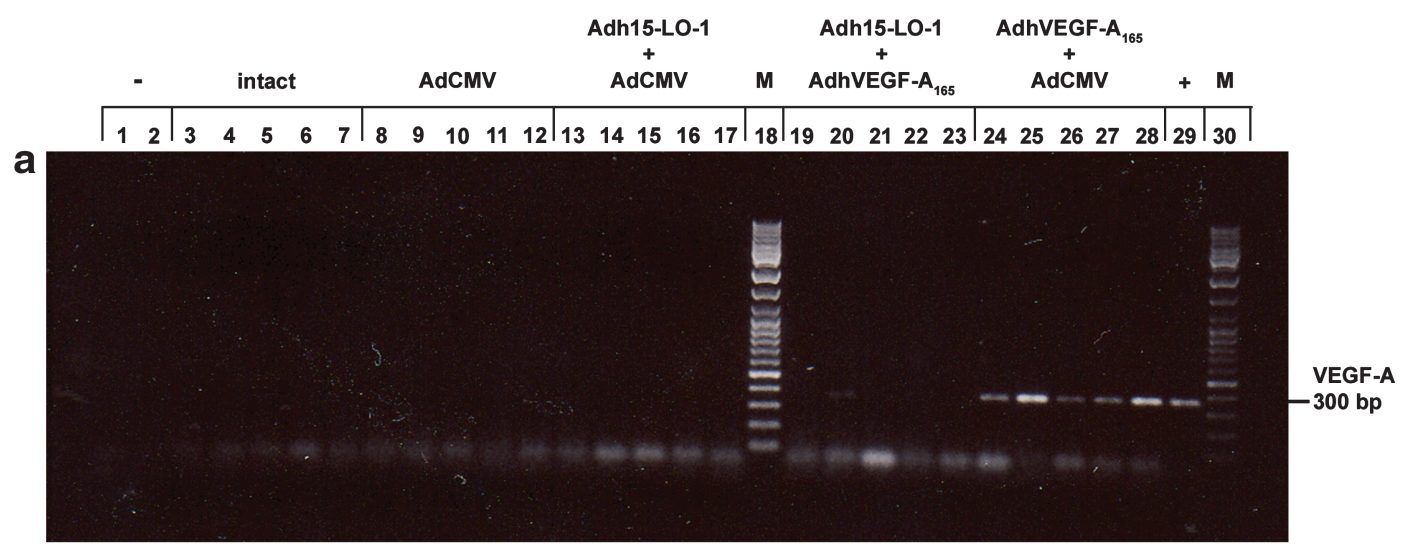

b

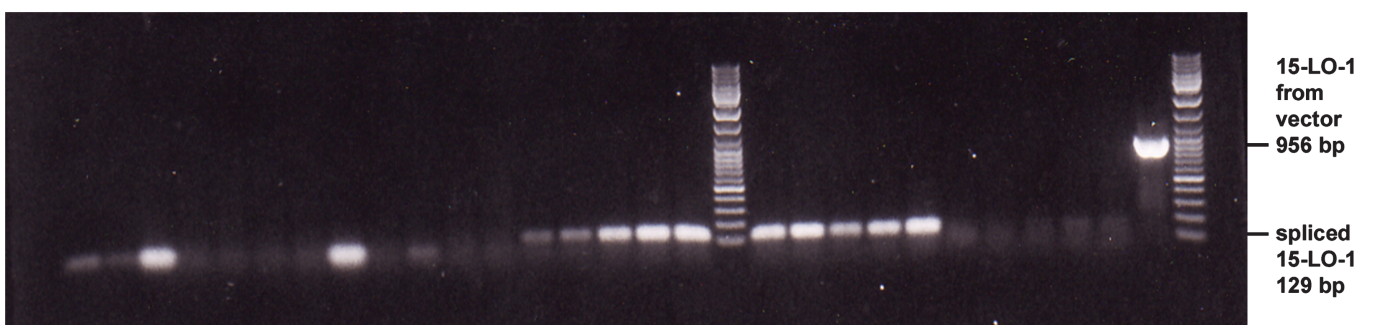

c

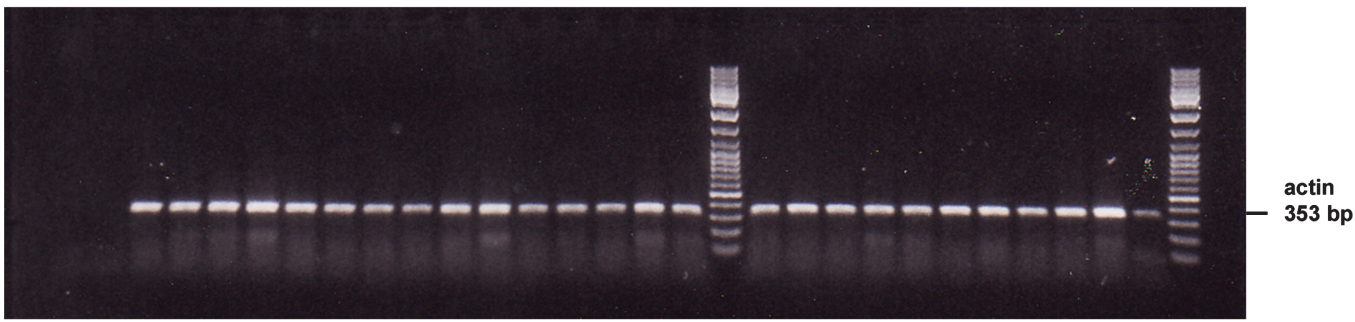

d

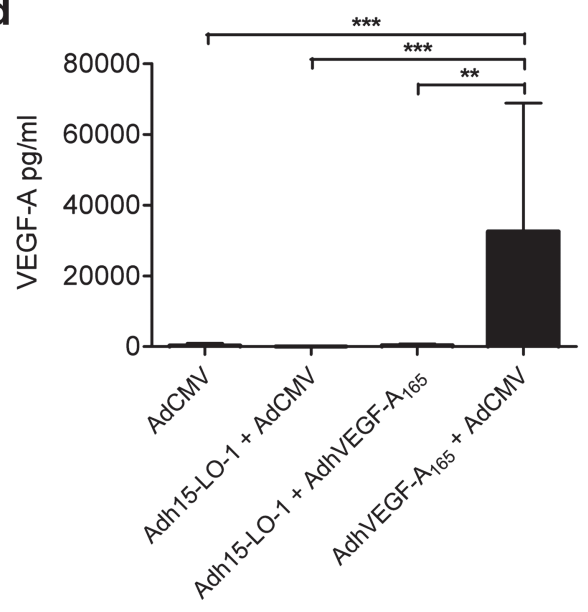

e

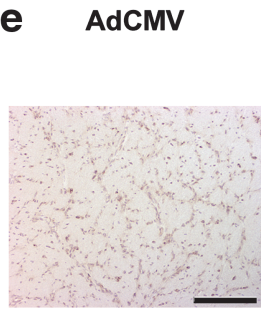

Adh15-LO-1

$+$ AdhVEGF-A

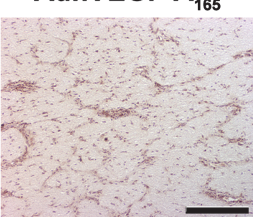

Adh15-LO-1

$+$

AdCMV

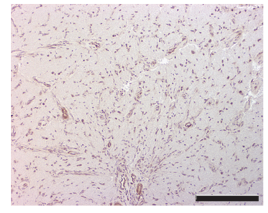

AdhVEGF-A AdCMV

FIG. 5. Adh15-LO-1 reduces mRNA expression and prevents protein production of transduced human VEGF-A 165 . Shown is the RT-PCR analysis of (a) transduced human VEGF-A 165 , (b) transduced human 15-LO-1, and (c) endogenous rabbit $\alpha$-actin from eye samples. From the left: (1) negative control from RT-PCR; (2) negative control from cDNA synthesis; (3-7) intact eyes; (8-12) AdCMV-transduced eyes; (13-17) Adh15-LO-1 plus AdCMV-transduced eyes; (18) molecular weight marker; (19-23) Adh15-LO-1 plus AdhVEGF-A 165 -transduced eyes; (24-28) AdhVEGF-A 165 plus AdCMV-transduced eyes; (29) positive control; (30) molecular weight marker. (d) Concentration of human VEGF-A in the vitreous as measured by ELISA. ${ }^{* * *} p<0.001$, AdhVEGF-A 165 plus AdCMV vs. AdCMV; ${ }^{* * *} p<0.001$, AdhVEGF-A 165 plus AdCMV vs. Adh15-LO-1 plus AdCMV; ${ }^{* *} p<0.01$, AdhVEGF-A 165 plus AdCMV vs. Adh15-LO-1 plus AdhVEGF-A 165 . (e) VEGF-A immunohistochemistry from the papilla, showing reduced VEGF-A expression in the 15-LO-1 treatment group compared with the AdhVEGF-A A $_{165}$-transduced group. Original magnification, $\times 100$; scale bars, $100 \mu \mathrm{m}$. 

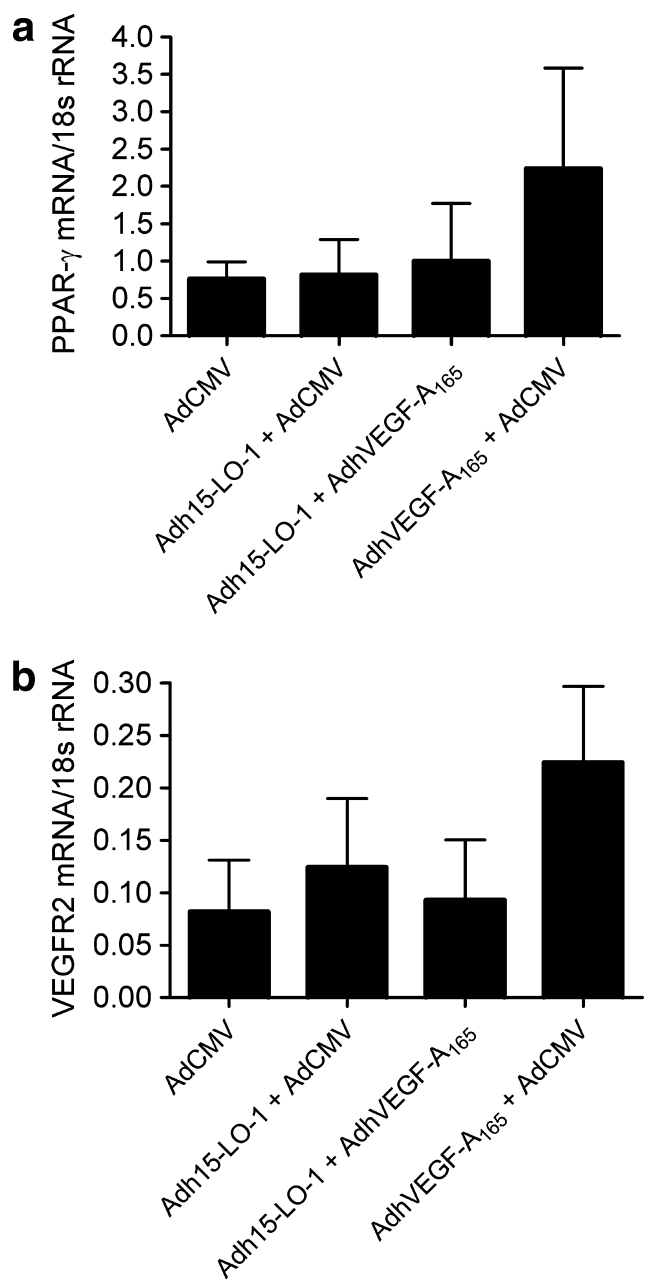

FIG. 6. Adh15-LO-1 prevents AdhVEGF-A 165 -induced mRNA expression of peroxisome proliferator-activated receptor- $\gamma$ (PPAR $\gamma$ ) and vascular endothelial growth factor receptor-2 (VEGFR2). Shown is a quantitative RT-PCR analysis of PPAR $\gamma$ and VEGFR2 expression from the transduced eye samples. (a) mRNA expression of endogenous rabbit PPAR $\gamma$. (b) mRNA expression of endogenous rabbit VEGFR2.

\section{Discussion}

We have previously shown that intravitreal adenoviral gene transfer of VEGF-A $\mathrm{A}_{165}$ induces neovascularization and increases vascular leakage in the rabbit eye (Kinnunen et al., 2006), thus producing a large animal model for VEGF- $\mathrm{A}_{165^{-}}$ dependent angioproliferative diseases of the eye. Transductions with $10^{10}, 5 \times 10^{10}$, and $10^{11} \mathrm{VP}$ of AdhVEGF- $\mathrm{A}_{165}$ result in a dose-dependent increase in the production of human VEGFA protein in the vitreous humor. Histological analyses reveals that significant differences in vascular structures already occur with $10^{10}$ VP of AdhVEGF-A 165 and that an inflammatory reaction is seen with the highest dose of $10^{11} \mathrm{VP}$. The dose of $5 \times 10^{10}$ VP of AdhVEGF-A 165 was selected for this study to achieve maximal expression of transduced human VEGF-A protein in the vitreous humor, while avoiding any adverse inflammatory effects. AdCMV control virus was used to bring the total number of viral particles to $10^{11} \mathrm{VP}$ in each group. The

animals were killed 6 days after gene transfer, because our previous study showed that the amount of transduced human VEGF-A protein was the highest at this time point and the histological analyses showed equally strong responses 6 days and 2 weeks after gene transfer (Kinnunen et al., 2006).

The expression of transduced VEGF- $\mathrm{A}_{165}$ was already reduced by 15 -LO-1 at the mRNA level. 15-LO-1 might affect the production of transduced human VEGF-A 165 either by preventing transcription or by destabilizing the transcript, or both. Both production and stability of VEGF-A 165 mRNA are highly regulated. Our AdhVEGF-A $\mathrm{A}_{165}$ construct lacks all the regulatory elements of the endogenous human VEGF- $\mathrm{A}_{165}$, as it contains only the protein coding region of VEGF- $\mathrm{A}_{165}$ under the control of the CMV promoter. Because the human 15-LO-1 cDNA in our adenoviral construct is also under the control of the CMV promoter, and there was no reduction in the expression of transduced human 15-LO-1 in the treatment group, it is highly unlikely that the reduction in mRNA expression of VEGF- $\mathrm{A}_{165}$ would be caused by blocking the CMV promoter. Thus, the most likely explanation is that 15LO-1 expression and/or its lipid hydroperoxide reaction products led to destabilization of the VEGF-A 165 transcript by an as yet unidentified mechanism that would affect the coding sequence of VEGF-A $\mathrm{A}_{165}$.

The VEGF-A 165 -induced expression of both PPAR $\gamma$ and VEGFR2 was prevented in the 15-LO-1 treatment group. The 15-LO-1 product 13-HODE is an endogenous activator and ligand of PPAR $\gamma$ (Nagy et al., 1998). Interestingly, it has been shown in a rabbit eye model that PPAR $\gamma$ binding to the VEGFR2 promoter induces VEGFR2 expression, but ligand binding to PPAR $\gamma$ actually results in an inhibition of VEGFR2 expression (Sassa et al., 2004). PPAR $\gamma$ ligands have also been shown to inhibit choroidal (Murata et al., 2000) and corneal neovascularization (Xin et al., 1999; Panigrahy et al., 2002; Sarayba et al., 2005). We hypothesize, that 15-LO-1 affects VEGF-A 165 -induced neovascularization both in transduced cells and via its secreted products. Thus, 15-LO-1 expression in cells next to the vascular endothelial cells (ECs) directly inhibits VEGF- $\mathrm{A}_{165}$ expression and prevents angiogenic signal transduction events mediated by secreted VEGF-A $\mathrm{A}_{165}$, whereas in 15-LO-1-transduced ECs the 15-LO-1 products prevent PPAR $\gamma$-induced VEGFR2 expression.

In conclusion, we have shown that intravitreal Adh15-LO1 gene transfer prevents all angiogenic effects induced by AdhVEGF-A $A_{165}$ in the eyes. The mechanism for the inhibition involves prevention of the expression of VEGF-A 165 at the mRNA level, resulting also in the reduced expression of PPAR $\gamma$ and VEGFR2. Therefore, 15-LO-1 gene transfer is a potential new treatment option for VEGF-induced pathological angiogenesis in the eyes.

\section{Acknowledgments}

This study was supported by grants from the University of Kuopio, the Finnish Foundation for Cardiovascular Research, the Academy of Finland, EU grant Baculogenes (LSHB-CT-2006-037541), the Orion-Farmos Research Foundation, and the Ark Therapeutics Group. The authors thank Ms. Anne Martikainen, Ms. Sari Järveläinen, Ms. Tiina Koponen, Ms. Seija Sahrio, and Ms. Marja Poikolainen for technical assistance. 


\section{Author Disclosure Statement}

No competing financial interests exist.

\section{References}

Aggarwal, N.T., Holmes, B.B., Cui, L., Viita, H., Ylä-Herttuala, S., and Campbell, W.B. (2007). Adenoviral expression of 15lipoxygenase-1 in rabbit aortic endothelium: role in arachidonic acid-induced relaxation. Am. J. Physiol. Heart Circ. Physiol. 292, H1033-H1041.

Cathcart, M.K., and Folcik, V.A. (2000). Lipoxygenases and atherosclerosis: Protection versus pathogenesis. Free Radic. Biol. Med. 28, 1726-1734.

Chanez, P., Bonnans, C., Chavis, C., and Vachier, I. (2002). 15lipoxygenase: A Janus enzyme? Am. J. Respir. Cell. Mol. Biol. $27,655-658$.

Graham, F.L., Smiley, J., Russell, W.C., and Nairn, R. (1977). Characteristics of a human cell line transformed by DNA from human adenovirus type 5. J. Gen. Virol. 36, 59-74.

Kinnunen, K., Korpisalo, P., Rissanen, T.T., Heikura, T., Viita, H., Uusitalo, H., and Ylä-Herttuala, S. (2006). Overexpression of VEGF-A induces neovascularization and increased vascular leakage in rabbit eye after intravitreal adenoviral gene transfer. Acta Physiol. (Oxf). 187, 447-457.

Kroschwald, P., Kroschwald, A., Kuhn, H., Ludwig, P., Thiele, B.J., Hohne, M., Schewe, T., and Rapoport, S.M. (1989). Occurrence of the erythroid cell specific arachidonate 15lipoxygenase in human reticulocytes. Biochem. Biophys. Res. Commun. 160, 954-960.

Kuhn, H., and Chan, L. (1997). The role of 15-lipoxygenase in atherogenesis: Pro- and antiatherogenic actions. Curr. Opin. Lipidol. 8, 111-117.

Kuhn, H., Walther, M., and Kuban, R.J. (2002). Mammalian arachidonate 15-lipoxygenases: Structure, function, and biological implications. Prostaglandins Other Lipid Mediat. 6869, 263-290.

Laitinen, M., Makinen, K., Manninen, H., Matsi, P., Kossila, M., Agrawal, R.S., Pakkanen, T., Luoma, J.S., Viita, H., Hartikainen, J., Alhava, E., Laakso, M., and Ylä-Herttuala, S. (1998). Adenovirus-mediated gene transfer to lower limb artery of patients with chronic critical leg ischemia. Hum. Gene Ther. 9, 1481-1486.

Murata, T., He, S., Hangai, M., Ishibashi, T., Xi, X.P., Kim, S., Hsueh, W.A., Ryan, S.J., Law, R.E., and Hinton, D.R. (2000). Peroxisome proliferator-activated receptor- $\gamma$ ligands inhibit choroidal neovascularization. Invest. Ophthalmol. Vis. Sci. 41, 2309-2317.

Nadel, J.A., Conrad, D.J., Ueki, I.F., Schuster, A., and Sigal, E. (1991). Immunocytochemical localization of arachidonate 15lipoxygenase in erythrocytes, leukocytes, and airway cells. J. Clin. Invest. 87, 1139-1145.

Nagy, L., Tontonoz, P., Alvarez, J.G., Chen, H., and Evans, R.M. (1998). Oxidized LDL regulates macrophage gene expression through ligand activation of PPAR $\gamma$. Cell 93, 229-240.

Panigrahy, D., Singer, S., Shen, L.Q., Butterfield, C.E., Freedman, D.A., Chen, E.J., Moses, M.A., Kilroy, S., Duensing, S., Fletcher, C., Fletcher, J.A., Hlatky, L., Hahnfeldt, P., Folkman, J., and Kaipainen, A. (2002). PPAR $\gamma$ ligands inhibit primary tumor growth and metastasis by inhibiting angiogenesis. J. Clin. Invest. 110, 923-932.

Pidgeon, G.P., Lysaght, J., Krishnamoorthy, S., Reynolds, J.V., O'Byrne, K., Nie, D., and Honn, K.V. (2007). Lipoxygenase metabolism: roles in tumor progression and survival. Cancer Metastasis Rev. 26, 503-524.
Rissanen, T.T., Markkanen, J.E., Arve, K., Rutanen, J., Kettunen, M.I., Vajanto, I., Jauhiainen, S., Cashion, L., Gruchala, M., Narvanen, O., Taipale, P., Kauppinen, R.A., Rubanyi, G.M., and Ylä-Herttuala, S. (2003a). Fibroblast growth factor 4 induces vascular permeability, angiogenesis and arteriogenesis in a rabbit hindlimb ischemia model. FASEB J. 17, 100-102.

Rissanen, T.T., Markkanen, J.E., Gruchala, M., Heikura, T., Puranen, A., Kettunen, M.I., Kholova, I., Kauppinen, R.A., Achen, M.G., Stacker, S.A., Alitalo, K., and Ylä-Herttuala, S. (2003b). VEGF-D is the strongest angiogenic and lymphangiogenic effector among VEGFs delivered into skeletal muscle via adenoviruses. Circ. Res. 92, 1098-1106.

Sarayba, M.A., Li, L., Tungsiripat, T., Liu, N.H., Sweet, P.M., Patel, A.J., Osann, K.E., Chittiboyina, A., Benson, S.C., Pershadsingh, H.A., and Chuck, R.S. (2005). Inhibition of corneal neovascularization by a peroxisome proliferator-activated receptor- $\gamma$ ligand. Exp. Eye Res. 80, 435-442.

Sassa, Y., Hata, Y., Aiello, L.P., Taniguchi, Y., Kohno, K., and Ishibashi, T. (2004). Bifunctional properties of peroxisome proliferator-activated receptor $\gamma 1$ in KDR gene regulation mediated via interaction with both Sp1 and Sp3. Diabetes 53, 1222-1229.

Sigal, E., Craik, C.S., Highland, E., Grunberger, D., Costello, L.L., Dixon, R.A., and Nadel, J.A. (1988). Molecular cloning and primary structure of human 15-lipoxygenase. Biochem. Biophys. Res. Commun. 157, 457-464.

van Leyen, K., Duvoisin, R.M., Engelhardt, H., and Wiedmann, M. (1998). A function for lipoxygenase in programmed organelle degradation. Nature 395, 392-395.

Viita, H., and Ylä-Herttuala, S. (2000). Effects of lipoxygenases on gene expression in mammalian cells. In Antioxidant and Redox Regulation of Genes. C.K. Sen, H. Sies, and P.A. Baeuerle, eds. (Academic Press, San Diego, CA) pp. 339-358.

Viita, H., Markkanen, J., Eriksson, E., Nurminen, M., Kinnunen, K., Babu, M., Heikura, T., Turpeinen, S., Laidinen, S., Takalo, T., and Ylä-Herttuala, S. (2008). 15-Lipoxygenase-1 prevents vascular endothelial growth factor A- and placental growth factor-induced angiogenic effects in rabbit skeletal muscles via reduction in growth factor mRNA levels, NO bioactivity, and downregulation of VEGF receptor 2 expression. Circ. Res. 102, 177-184.

Witmer, A.N., Vrensen, G.F., van Noorden, C.J., and Schlingemann, R.O. (2003). Vascular endothelial growth factors and angiogenesis in eye disease. Prog. Retin. Eye Res. 22, 1-29.

Xin, X., Yang, S., Kowalski, J., and Gerritsen, M.E. (1999). Peroxisome proliferator-activated receptor $\gamma$ ligands are potent inhibitors of angiogenesis in vitro and in vivo. J. Biol. Chem. 274, 9116-9121.

Address correspondence to: Dr. Seppo Ylä-Herttuala Department of Biotechnology and Molecular Medicine A.I. Virtanen Institute for Molecular Sciences University of Kuopio P. O. Box 1627 FI-70211 Kuopio, Finland E-mail: seppo.ylaherttuala@uku.fi

Received for publication April 21, 2009; accepted after revision August 19, 2009.

Published online: November 13, 2009. 